\title{
Cancer burden in Nepal: a call for action
}

\begin{abstract}
Globally, cancer remains the leading cause of morbidity and mortality. Cancer is the cellular transformation of normal cells into tumor cells which originate through multistage processes. It is due to one's genetic predisposition, physical, chemical and some biological factors. It is a non-communicable disease and has high mortality rate. Compared to developed countries the burden of the disease is higher in low and middle-income countries including Nepal. Treatment of cancer remains very costly requiring sophisticated infrastructure, highly specialized health personnel and expensive drugs. Patients from poor countries can hardly afford these expensive treatments. Nepal is also a low-income country with per capita income of around only 1000 dollars per annum. Rapid urbanization with unplanned settlement, food and air pollution, under-nutrition and lack of adequate sophisticated health care facility for early diagnosis and treatment has led to alarming surge in morbidity due to cancer. This communication is aimed at highlighting the burden and discussing the possible control measures to be taken at state level in Nepal.
\end{abstract}

Keywords: cancer, nepal, awareness, morbidity, prevention and treatment
Volume 7 Issue 5 - 2018

\author{
Bhuvan Saud,' Saroj Adhikari, ${ }^{2}$ Mamata \\ Sherpa Awasthi ${ }^{3}$ \\ 'Department of Medical Laboratory Technology, Janamaitri \\ Foundation Institute of Health Sciences (JFIHS), Nepal \\ ${ }^{2}$ Manmohan Cardiothoracic Vascular and Transplant Center, \\ Tribhuvan University, Nepal \\ ${ }^{3}$ Department of Nursing, Janamaitri Foundation Institute of \\ Health Sciences (JFIHS), Nepal
}

\author{
Correspondence: Saroj Adhikari, Manmohan Cardiothoracic \\ Vascular and Transplant Center, Institute of Medicine (IOM), \\ Tribhuvan University, Kathmandu, Nepal, \\ Email saroj.adhikari00977@gmail.com
}

Received:September 142018 | Published: September 21, 2018
Abbreviations: WHO, World Health Organization; NHRC, Nepal Health Research Council; OPD, Out Patients Department; DOHS, Department of Health Services; IARC, International Agency for Research on Cancer

\section{Short communication}

According to World Health Organization (WHO), 9.6 million people died of cancer in 2018 of which $70 \%$ were from middle and low-income countries. Cancer is also the second leading cause of deaths globally. The leading causes of deaths due to cancer worldwide were highest for lung cancer, followed by colorectal cancer, stomach cancer, liver cancer and breast cancer. ${ }^{1}$ A report published by WHO has shown that cancer mortality in Nepal is higher in females as compare to males-7,400 and 6,900 respectively. The major risk factors are tobacco smoking, excessive alcohol consumption, household solid fuel, physical inactivity and obesity, ${ }^{2}$ along with others like environment pollution and excessive pesticides in vegetable and fruits. ${ }^{3,4}$ Based on hospitals' data approximately $8,000-10,000$ new cases of cancer are identified every year in Nepal. ${ }^{5}$ Kathmandu, the capital of Nepal has been listed on top of the 10 most cancer affected districts in Nepal followed by Sunsari, Morang, Chitwan, Jhapa, Lalitpur, Rupandehi, Kaski, Nawalparasi and Bhaktapur. ${ }^{6}$ A retrospective study analysis data over the four year period between 2010 and 2013 of twelve hospital situated in Nepal showed that cancer of bronchus and lung, stomach and larynx are most common among men. In female, most common cancers were listed to be cervical/ uteri, breast, bronchus and lungs. ${ }^{7}$ According to a study conducted in central region of Nepal, of total 240 cancer patients, Newar were $30.42 \%$, Chhetri were $22.92 \%$ and Brahmin were $20 \%$. Most of the cancer cases were documented from Kathmandu, Lalitpur, Bhaktapur and Sindhupalchowk districts. ${ }^{8}$ Showed the age specific incidence of cancer in central Nepal. They showed that rapid increase in incidence was among 45-49age group in male and 30-34age group in female, the highest incidence rate was between age groups 70-74years in male and 65-69 age group in female. ${ }^{9}$ By 2020 the incidence rate of cancer per 100,000 is estimated to be 41.4 in female and 38.5 in male. ${ }^{10}$
Annual report published by Department of Health Services (DoHS), Nepal in 2018 depicted the morbidity of various cancers in all seven provinces between 2016 and 2017. A total of 13,997 cases were reported in Out Patients Department (OPD) attending patients all over Nepal. 9053 cases of different cancers were reported from Province 3 and 3865 from Province 4. The least number of cases were reported from Province 6 (70 cases). The higher number of cases reported in Province 3 and 4 may be due to easier accessibility to higher health care facilities and very low numbers in province 6 due to inaccessibility to better health care facilities. Overall, highest morbidity was noted for Breast and Lung cancer, 1863 and 1885 respectively, followed by Cervical/Uteri Cancer-1425, Head and Neck Cancer-866 all over Nepal as shown in Figure 1. ${ }^{11}$ Screening and early detection facilities are limited to the central cities of the nation. The rural communities are deprived of screening facility in primary public health care centers. In context of Nepal, the burden due to cancer is due to higher cost of treatment, lower economic status and unavailability of adequate radiation equipment and limited number and inadequate quantity of chemotherapeutic molecule. Estimated cost of cancer treatment in a Government hospital like Bir Hospital (US\$ 68.22) is much lesser compared to private hospitals (US\$ 200-250). ${ }^{12}$ Besides this, the cost of chemotherapy regimen, radiotherapy, diagnosis and other surgical procedure add significant economic burden to the cancer victims.

There is no mandatory health insurance system in the country and the number of free treatment facilities are not adequate. People have to bear all expenses by themselves and often end in selling their properties and belongings for treatment. The government of Nepal is trying to address the escalating cancer burden by introducing various programs and treatment subsidies. In 2018, Nepal Health Research Council (NHRC) has launched Population Based Cancer Registry to collect cancer patients' data across the nation. It will provide information to the concerned bodies on the burden of cancer and its control activities. The NHRC is taking technical support from World Health Organization, Country Office, Nepal; International Agency for Research on Cancer (IARC), France and IARC Regional Hub, 
Mumbai to implement the program..$^{13}$ The government plans for giving financial assistance of NRs. 500,000 to people diagnosed with cancer to cover expenses for treatment, chemotherapies and investigations. ${ }^{14}$ Certain tertiary care government hospitals are providing free treatment facilities. 2,744 individuals received fee cancer treatment in the fiscal year 2015-2016. ${ }^{11}$ Various non-government organizations like Nepal Cancer Relief Society, Cancer Society Nepal, Cancer Care Nepal and Astha Cancer Foundation are also working on cancer awareness, prevention and diagnosis. The government has imposed heavy taxes on tobacco products and liquor to discourage their use. The government is making efforts to address the present cancer burden but this is not enough. Much is still needed to address the surge in cancer cases in recent times. All concerned stakeholders should actively focus on control and prevention of cancer before it is too late. Primarily, public awareness and health education should be emphasized to promote the avoidance of risk factors and change unhealthy living and fooding habits. The government should avail free and easily accessible vaccination against Human Papilloma Virus for all women of high risk age group. Mother-groups in communities have been found to be very effective in control of smoking and alcoholics and other unsocial activities. Such groups should be formed actively in all communities and oriented on the adverse effects of smoking and alcohol consumption, improper pesticides use and unhealthy life style. Cancer screening facilities should be availed at every health care centers of the government and the health care personnel should be trained accordingly. At least one sophisticated diagnostic and treatment center for cancer needs to be established in every province. This will on one hand help in early diagnosis and treatment and on the other hand decrease economic burden of individuals and government for treating late stage cancers.

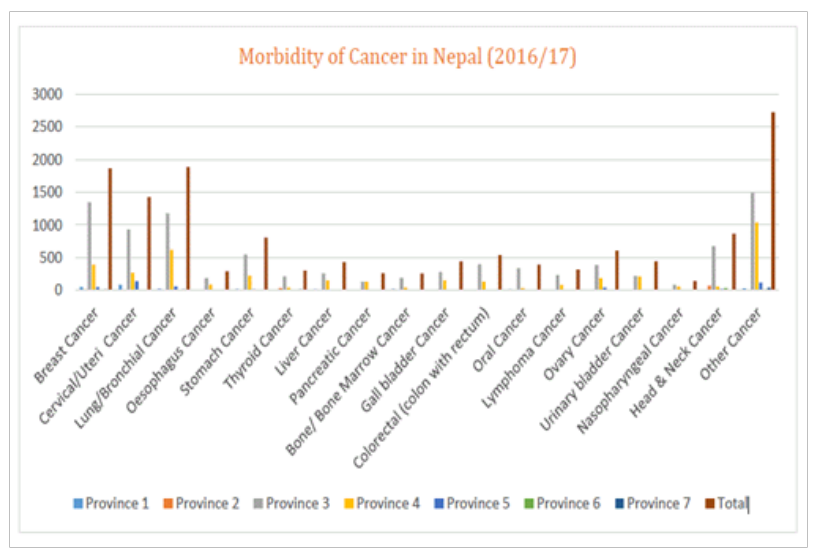

Figure I Out patients department (OPD) morbidity of cancer in Nepal."

\section{Acknowledgments}

None.

\section{Conflict of interest}

Author declares that there is no conflict of interest.

\section{References}

1. World Health Organization (WHO). Cancer. France; 2018.

2. World Health Organization (WHO). Cancer Country Profiles. Nepal; 2018.

3. Saud B, Paudel G. The Threat of Ambient Air Pollution in Kathmandu. Journal of Environmental and Public Health; 2018.

4. Pesticides use health hazards. The Himalayan Times; 2018.

5. Subedi K, Sharma P. Cancer treatment in Nepal: a historical background, development of treatment facilities, epidemiology and challenges for prevention and control of cancer. Austr-Asian J Canc. 2012;11(3):205212.

6. Lifestyle choice increasing cancer cases. The Kathmandu Post; 2018

7. Poudel KK, Huang Z, Neupane PR, et al. Hospital-Based Cancer Incidence in Nepal from 2010 to 2013. Nepal Journal of Epidemiology. 2017;7(1):659-665.

8. Khan GM, Thappa R, Adhikari D. Cancer prevalence trend in central region of Nepal. Journal of Chitwan Medical College. 2013;3(3):22-25.

9. Poudel KK, Huang Z, Neupane PR. Age specific incidence of five major cancers in Nepal. Journal of Epidemiology. 2016;6(2):565-573.

10. Poudel KK, Huang Z, Neupane PR, et al. Prediction of the Cancer Incidence in Nepal. Journal of Cancer Prevention. 2017;18(1):165-168.

11. Department of Health Services (DoHS). Annual Report. Nepal; 2018.

12. Piya MK, Acharya SC. Oncology in Nepal. South Asian Journal of Cancer. 2012;1(1):5-8.

13. Nepal Health Research Council (NHRC). Population Based Cancer Registry Launched by Nepal Health Research Council. Nepal; 2018.

14. Cancer Patients Like to get Rs 500000 for treatment. The Himalayan Times. 2018 